\title{
XFEM-Based Analysis for Crack Growth Characteristics of Diffusion Bonded Laminates of Titanium Alloy with Localized Nonwelded Zone
}

\author{
Yang Liu, ${ }^{1}$ Yongcun Zhang, ${ }^{1}$ Shutian Liu, ${ }^{1}$ Shan Xiao, ${ }^{1}$ \\ Xiangming Wang, ${ }^{2}$ and Yanpeng Sun ${ }^{2}$ \\ ${ }^{1}$ State Key Laboratory of Structural Analysis for Industrial Equipment, Department of Engineering Mechanics, \\ Dalian University of Technology, Dalian 116024, China \\ ${ }^{2}$ Shenyang Aircraft Design Research Institute, Shenyang 110035, China
}

Correspondence should be addressed to Shutian Liu; stliu@dlut.edu.cn

Received 24 June 2013; Accepted 7 August 2013

Academic Editor: Song Cen

Copyright (C) 2013 Yang Liu et al. This is an open access article distributed under the Creative Commons Attribution License, which permits unrestricted use, distribution, and reproduction in any medium, provided the original work is properly cited.

\begin{abstract}
Titanium-alloy laminates fabricated by sheet materials using diffusion bonding process have drawn more and more attention in the recent years. Proper placement of nonwelded zones on the diffusion bonding (DB) interface within titanium-alloy laminates as crack arrest zones can improve damage tolerance. To achieve the optimal damage tolerance via designing non-welded zones, it is necessary to study fatigue crack growth characteristics for this type of laminates by adjusting all the relevant parameters such as geometrical sizes, locations, and the number of the nonwelded zones, which is highly time consuming. Therefore it is essential to develop a reliable and quick method to analyze the fatigue crack growth characteristics for titanium-alloy laminates with non-welded zones. In this paper, the extended finite element method (XFEM) which was employed to simulate the fatigue crack growth process and the applicability of this method to capture fatigue crack growth characteristics of titanium-alloy laminates with localized non-welded zones was also studied. The numerical results were compared with the experiment data, and the agreement on numerical and experimental results illustrated that the specific crack growth characteristics can be captured by using XFEM, thereby verifying the applicability of XFEM in the analysis of fatigue crack growth of the laminates with non-welded zones. The influence of non-welded zones on the fatigue crack growth was then discussed.
\end{abstract}

\section{Introduction}

Titanium alloys have over the years proven themselves to be technically superior and cost effective materials for a wide range of applications spanning the industries of aerospace, marine, and even commercial products [1]. This is because of their excellent combination of mechanical properties such as high specific strength, immunity to corrosion in sea water environment, good erosion resistance in environments spanning a range of aggressiveness, and importantly their acceptable mechanical properties at elevated temperatures coupled with an intrinsic capability to withstand and safely function at elevated temperatures. The noticeable attractive properties of titanium alloys have facilitated their selection and enhanced their use in aviation and a spectrum of other performance-critical applications [2].
However, there is a disadvantage that the residual life is relatively short once the damage appears in the structure which is made of common titanium alloy. (Damage is inevitable actually.) Thus the common titanium alloys are ineffective in damage tolerance design [3], and developing the technology that is able to improve the damage tolerance becomes an important issue. At present, some damage tolerance type titanium alloys, such as Ti-6Al-4VELI, Ti6-22-22S, have been applied in advanced airplane, which greatly improved the service life and combat effectiveness of airplanes.

Damage-tolerance-design strategy gets more and more attention in modern aircraft design. It takes the intrinsic/ discrete damage, large area manufacturing flaws, or severe accidental damage into consideration and ensures that 
the remaining structure will withstand reasonable loads without failure or excessive structural deformation until the damage is detected. In order to improve the applicability of titanium alloys to damage-tolerance-design, one traditional method is through microstructural control, and another method is through the use of submacro laminated structures [4]. Some experimental investigations demonstrate that the DB interfaces in the titanium alloy-laminates which are made by diffusion bonding process have significant inhibitory effect on the growth of the fatigue crack $[5,6]$. Something more interesting, is that the diffusion bonded laminates of TC4 titanium alloy may have longer fatigue life if the localized nonwelded zone exists in the DB interfaces. This indicates that the defects may achieve significant inhibition of crack growth when the defects lie in the proper position. It will be a good approach to increase the structure fatigue life by reasonably arranging the defects in DB interfaces. To implement the reasonable arrangement of defects, the influence of the defect effects on the fatigue crack growth characteristics should be known clearly. At present, the crack growth characteristics mostly are conducted through experiments, and hence it is necessary to develop the rapid numerical analytical method for studying the mechanism of the crack growth in the titanium alloy-laminates.

The recently proposed XFEM can describe the discontinuity and singularity by introducing the enrichment function to the shape function of the conventional finite element method (CFEM), and it exhibits a unique advantage in the analysis of discontinuous problem [7-12]. Crack is a typical discontinuity, and XFEM will be an effective method in researching fatigue crack growth characteristics in the laminates of titanium alloys.

In this paper, the XFEM method based on the ABAQUS platform is employed for analyzing crack growth characteristics in the diffusion bonded laminates of TC4 titanium alloys, and the results obtained are compared with the experimental results given in [6] to verify that XFEM is able to get the true crack growth characteristic and an effective method for crack growth analysis in the laminates of titanium alloys. In addition, through the comparison between the crack growth characteristics in the laminates with and without nonwelded zones, this paper reveals the mechanism that is how the nonwelded zone increases the fatigue life. And the results will give the technical support in the damage tolerance design of titanium-alloy laminates.

\section{XFEM-Based Crack Growth Analysis}

The enrichment function in XFEM can accurately describe the crack or material interface's discontinuity and singularity that exit inside the element. So the mesh in XFEM can be independent of the structure's geometrical or physical interface, and that avoids the limit that there must be very fine grids near crack tip or material interface when using traditional finite element method, and it is more attractive that there needs no remeshing in analyzing the crack growth problem in XFEM. XFEM has all the advantages in CFEM.

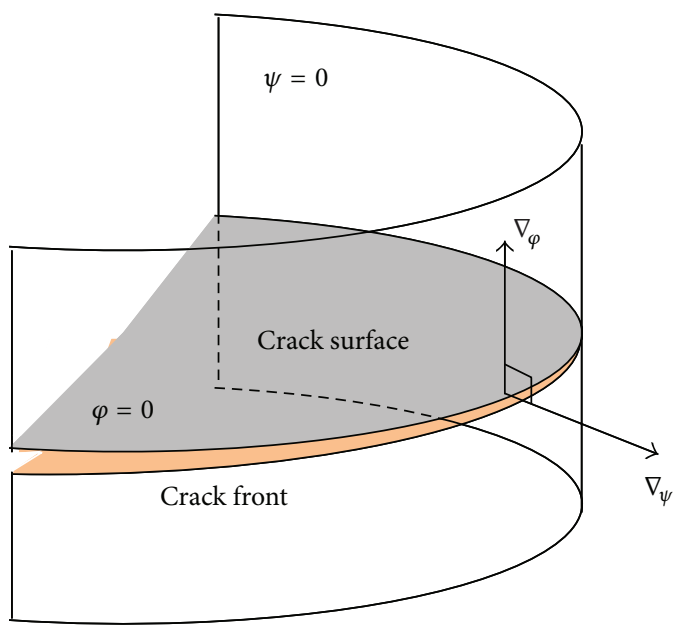

FIGURE 1: Level set method for interface described.

For this reason, the form of element stiffness matrix in XFEM is inline with that in CFEM, and the implementation of XFEM can make full use of the CFEM program that already exists.

2.1. Description of Discontinuous Interface. The level set method is a numerical technique for tracking the evolution of interfaces. In this method, the interface is represented as the zero level set of a function $\varphi(x, t)$. This function is one dimension higher than the dimension of the interface. In general, a moving interface in $n$ dimensional ( $2 \mathrm{D}$ or $3 \mathrm{D})$ space can be formulated as

$$
\begin{gathered}
\Gamma(t)=\left\{x \in R^{n}: \varphi(x, t)=0\right\}, \\
\varphi(x, t)= \pm \min _{x_{r} \in r(t)}\left\|x-x_{r}\right\| .
\end{gathered}
$$

The level set function usually uses signal distance function to be constructed. Where $x_{r}$ are the points located on the crack interface and $r(t)$ represent the whole crack surface. The whole domain is cut into two parts $\varphi>0$ and $\varphi<$ 0 by the zero level set function $\varphi=0$. Another level set function $\psi(x, t)$ is introduced to describe the crack tip by the intersection set of the two level set functions, shown in Figure 1.

Consider

$$
\psi(x, t)=\left(x-x^{*}\right) \cdot(\vec{n} \times \vec{t}),
$$

where $\vec{t}$ is the unit tangent vector and $\vec{n}$ is the unit vector normal to the crack surface. $x^{*}$ is the crack tip coordinates.

The description of crack growth can be got from the evolution of the level set, and the details refer to the literature [14].

2.2. XFEM Displacement Mode. The displacement field $u^{h}$ in XFEM consists of two parts:

$$
u^{h}=\sum_{I} N_{I}(x) u_{I}+\phi(x)
$$

where $N_{I}(x)$ is the conventional shape function and $u_{I}$ is the degree of freedom (DOF) of standard nodes. $\phi(x)$ is 
the enrichment function. In the crack tip element, $u^{h}$ can be represented [7]:

$$
u^{h}=\sum_{I} N_{I}(x) u_{I}+\sum_{I} N_{I}(x) \Phi(x) q_{I},
$$

where $\Phi(x)$ always takes linear combination of the following function base:

$$
\Phi(x)=\sqrt{r}\left[\sin \frac{\theta}{2}, \sin \frac{\theta}{2} \sin \theta, \cos \frac{\theta}{2}, \cos \frac{\theta}{2} \sin \theta\right],
$$

where $r$ and $\theta$ are the polar coordinates in the crack tip local coordinates and the enrichment function $\phi(x)$ uses the following form in the elements crossed by crack [15]:

$$
\phi(x)=N_{I} H(\varphi(x)),
$$

where $\varphi(x)$ is the level set function and $H(\varphi(x))$ is the jump function.

Consider

$$
H(\varphi(x))= \begin{cases}1, & \varphi(x) \geq 0 \\ -1, & \varphi(x)<0 .\end{cases}
$$

The displacement mode in the crossed elements is

$$
u^{h}=\sum_{I} N_{I}(x) u_{I}+\sum_{I} N_{I}(x) H(\varphi(x)) q_{I} .
$$

The junction between the enriched elements and the common elements will produce mixed elements, and the literature [16-19] discussed that particularly.

2.3. XFEM Discrete Control Equation. The weak form of XFEM discrete control equation can be described as follows in linear elasticity problems [12]:

$$
\begin{array}{r}
\int_{\Omega^{h}} \sigma: \delta \varepsilon^{h} \mathrm{~d} \Omega=\int_{\Omega^{h}} \mathbf{b}: \delta \mathbf{u}^{h} \mathrm{~d} \Omega+\int_{\partial \Omega_{t}^{h}} \overline{\mathbf{t}} \cdot \delta \mathbf{u}^{h} \mathrm{~d} \Gamma, \\
\forall \delta \mathbf{u}^{h} \in \mathbf{U}_{0}^{h},
\end{array}
$$

where $\overline{\mathbf{t}}$ is the surface force and $\mathbf{b}$ is the body force. $\mathbf{u}^{h}$ and $\delta \mathbf{u}^{h}$ are the trial function and test function in XFEM. Taking the $\mathbf{u}^{h}$ and $\delta \mathbf{u}^{h}$ into (9) and using the arbitrariness of node variation, we can get the discrete linear system of equations:

$$
\mathbf{K d}=\mathbf{f} .
$$

The form of equilibrium equation previously mentioned is inline with the CFEM. $\mathbf{K}$ is the global stiffness matrix, $\mathbf{f}$ is the load vector, and $\mathbf{d}$ is the displacement vector. $\mathbf{K}$ and $\mathbf{f}$ consist of each element follows the node number. The contribution of each element is expressed as follow:

$$
\begin{aligned}
& \mathbf{k}_{i j}^{e}=\left[\begin{array}{ccc}
\mathbf{k}_{i j}^{u u} & \mathbf{k}_{i j}^{u a} & \mathbf{k}_{i j}^{u b} \\
\mathbf{k}_{i j}^{a u} & \mathbf{k}_{i j}^{a a} & \mathbf{k}_{i j}^{a b} \\
\mathbf{k}_{i j}^{b u} & \mathbf{k}_{i j}^{b a} & \mathbf{k}_{i j}^{b b}
\end{array}\right], \\
& \mathbf{f}_{i}^{e}=\left\{\begin{array}{llllll}
\mathbf{f}_{i}^{u} & \mathbf{f}_{i}^{a} & \mathbf{f}_{i}^{b 1} & \mathbf{f}_{i}^{b 2} & \mathbf{f}_{i}^{b 3} & \mathbf{f}_{i}^{b 4}
\end{array}\right\}^{T} .
\end{aligned}
$$

The details of $\mathbf{k}$ and $\mathbf{f}$ are as follows:

$$
\begin{gathered}
\mathbf{k}_{i j}^{r s}=\int_{\Omega^{e}}\left(\mathbf{B}_{i}^{r}\right)^{T} \mathbf{D} \mathbf{B}_{j}^{s} \mathrm{~d} \Omega, \quad(r, s=u, a, b), \\
\mathbf{f}_{i}^{u}=\int_{\partial \Omega_{t}^{h} \cap \partial \Omega^{e}} N_{i} \overline{\mathbf{t}} \mathrm{d} \Gamma+\int_{\Omega^{e}} N_{i} \mathbf{b} \mathrm{d} \Omega, \\
\mathbf{f}_{i}^{a}=\int_{\partial \Omega_{t}^{h} \cap \partial \Omega^{e}} N_{i} H \overline{\mathbf{t}} \mathrm{d} \Gamma+\int_{\Omega^{e}} N_{i} H \mathbf{b} \mathrm{d} \Omega, \\
\mathbf{f}_{i}^{b \alpha}=\int_{\partial \Omega_{t}^{h} \cap \partial \Omega^{e}} N_{i} \Phi_{\alpha} \overline{\mathbf{t}} \mathrm{d} \Gamma+\int_{\Omega^{h}} N_{i} \Phi_{\alpha} \mathbf{b} \mathrm{d} \Omega, \quad(\alpha=1-4),
\end{gathered}
$$

where $\mathbf{B}_{i}^{a}, \mathbf{B}_{i}^{u}$, and $\mathbf{B}_{i}^{b}$ are the derivative matrixes of the shape function:

$$
\begin{aligned}
& \mathbf{B}_{i}^{u}=\left[\begin{array}{cc}
N_{i, x} & 0 \\
0 & N_{i, y} \\
N_{i, y} & N_{i, x}
\end{array}\right], \\
& \mathbf{B}_{i}^{a}=\left[\begin{array}{cc}
\left(N_{i} H\right)_{, x} & 0 \\
0 & \left(N_{i} H\right)_{, y} \\
\left(N_{i} H\right)_{, y} & \left(N_{i} H\right)_{, x}
\end{array}\right], \\
& \mathbf{B}_{i}^{b \alpha}=\left[\begin{array}{cc}
\left(N_{i} \Phi_{\alpha}\right)_{, x} & 0 \\
0 & \left(N_{i} \Phi_{\alpha}\right)_{, y} \\
\left(N_{i} \Phi_{\alpha}\right)_{, y} & \left(N_{i} \Phi_{\alpha}\right)_{, x}
\end{array}\right], \quad(\alpha=1-4), \\
& \mathbf{B}_{i}^{b}=\left[\begin{array}{llll}
\mathbf{B}_{i}^{b 1} & \mathbf{B}_{i}^{b 2} & \mathbf{B}_{i}^{b 3} & \mathbf{B}_{i}^{b 4}
\end{array}\right] .
\end{aligned}
$$

The derivation of the discrete control equation refers to the literature [20].

2.4. Fatigue Crack Growth Rule and Description of Crack Growth. We get the three energy release rate components at crack tip by virtual crack closure technique (VCCT) and calculate the equivalent energy release rate through (14) which Wu and Reuter [21] suggested. (In the equation, $a_{1}=$ $a_{2}=a_{3}=1$.) When the max equation energy release rate $G_{\mathrm{ME}}$ is bigger than the threshold of fatigue crack growth, the crack begins to grow. When the crack growth rule is satisfied, the crack growth length can be calculated by the Paris formula (15), and the crack grows normal to the direction of the maximum circumferential stress:

$$
\begin{gathered}
\frac{G_{E}}{G_{C}}=\left(\frac{G_{I}}{G_{I C}}\right)^{a_{1}}+\left(\frac{G_{I I}}{G_{I I C}}\right)^{a_{2}}+\left(\frac{G_{I I I}}{G_{I I C}}\right)^{a_{3}}, \\
\frac{d a}{d N}=C(\Delta G)^{n} .
\end{gathered}
$$

The XFEM in ABAQUS lacks the description of crack tip inside element; therefore the crack tip has to grow to the boundary of element. So there are some differences in calculating the crack growth length from the traditional method. It calculates the needed cycles that the crack grows given length (the length of crossed element), which instead of calculating the length crack grows given cycles $N$. Where $N$ gets from the needed cycles $N_{j}$ that each element at the crack tip is crossed by and get $\min \left(N_{j}\right)$ as the $N$ in current step. 


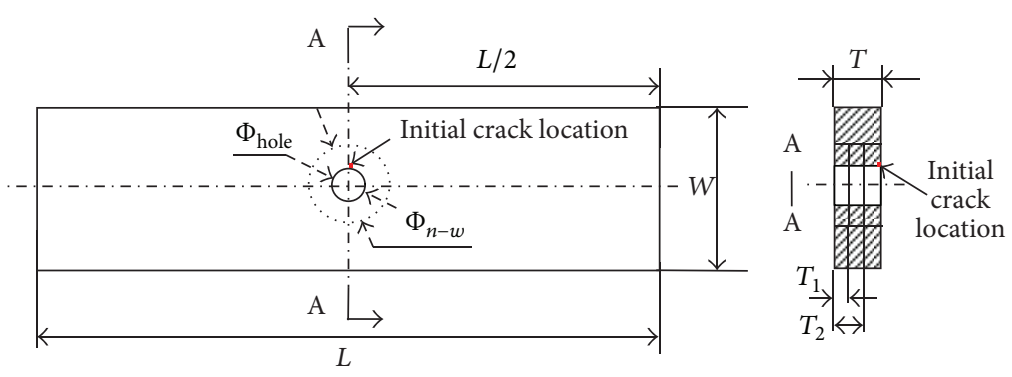

FIGURE 2: Model of the floor plan.

TABLE 1: Mechanical properties of TC4 [13].

\begin{tabular}{lccc}
\hline $\begin{array}{l}\text { Elastic } \\
\text { modulus }\end{array}$ & $\begin{array}{c}\text { Ultimate } \\
\text { strength }\end{array}$ & $\begin{array}{c}\text { Fracture } \\
\text { toughness }\end{array}$ & $\begin{array}{c}\text { Poisson's } \\
\text { ratio }\end{array}$ \\
\hline$E(\mathrm{GPa})$ & $\sigma_{b}(\mathrm{MPa})$ & $K_{\mathrm{IC}}(\mathrm{MPa} \sqrt{\mathrm{m}})$ & $v$ \\
110 & 913 & 78.3 & 0.34 \\
\hline
\end{tabular}

\section{The Specimen Properties}

Crack growth characteristics of diffusion bonded laminates of titanium alloys with localized nonwelded zone can be obtained by the XFEM based on the ABAQUS platform. In order to compare with the experimental data given in [6], the specimen shown in Figure 2 is investigated as an example. The length $L$ is $180 \mathrm{~mm}$ and the width $W$ is $40 \mathrm{~mm}$, and there is a hole with $\Phi_{\text {hole }}=6 \mathrm{~mm}$ in the center. The overall thickness $T$ is $8 \mathrm{~mm}$, which consists of three layers of titanium-alloy plate, and their thicknesses are $3 \mathrm{~mm}, 2 \mathrm{~mm}$, and $3 \mathrm{~mm}$ from the upper layer to lower layer, respectively. A single-edge square notch with side length $0.5 \mathrm{~mm}$ and thickness $0.2 \mathrm{~mm}$ is located at the edge of the hole on the plate surface. In order to reveal the mechanism of how the nonwelded zone increases the fatigue life, two cases are taken into consideration. In case one, there are circular non-welded zones with diameter $\Phi_{n-w}=15 \mathrm{~mm}$ in the two DB interfaces as shown in Figure 2, and there is no non-welded zone in the DB interfaces in the other case.

The boundary condition of two ends is clamp, and it is in keeping with the tensile experiment just like it was considered in [6]. The tension-tension cyclic loading uses the stress rate $R=0.093$ and the stress peak $\sigma_{\max }=276 \mathrm{MPa}$. The Paris constants are $C=5.25 \times 10^{-8}$ and $n=2.85$, and the formula constants and material properties are from the literature [13]. The material properties are in Table 1 as follows.

\section{Results and Discussion}

4.1. Comparison with Experiment. The whole process of crack growth in the specimen is simulated by XFEM. The crack growth path is described in Figure 3, and the relation between crack growth rate and surface crack length along the direction of the aperture is shown in Figure 4. The experimental result of the relation between crack growth rate and surface crack length in [6] is also shown in Figure 5.
Figure 4 shows that the results obtained by XFEM agree well with the experimental data. Combined with the detail crack growth path described in Figure 3, the whole growth process of surface crack can be divided into three distinct stages. In the first stage, the crack growth rate increases as the fracture crack length gets longer. When the crack front along the thickness direction reaches the non-welded zone, the first stage ends and then the second stage begins. The crack growth rate decreases obviously, and this indicates that the non-welded zone can inhibit the crack growth significantly. The third stage will start when the crack front bypasses the boundary of the nonwelded zone; meanwhile, the crack growth rate increases rapidly and the residual strength of the structure decreases sharply. These evidence shows that the numerical simulation by XFEM can capture the characteristics of the crack growth.

The experimental data shown in Figure 6 illustrates that the times of fatigue cycle in the stage of crack initiation have huge discrepancy for different specimens. In order to compare the fatigue life in the crack growth stage with the results forecasted by XFEM, the crack initiation is ignored and the relationship between crack length and the cycles is considered from a given surface crack length (the length $a_{0}=$ $1.0 \mathrm{~mm}$ in this paper). The comparison between the predicted results and experiments is shown in Figure 7. Where $\Delta N=$ $N-N_{0}$, and $N_{0}$ represents the cycle number when the crack length reaches $a_{0}$. From Figure 7 , we can see that there are the same tendencies for three specimens, and the results by XFEM are accord with the experimental data. These indicate again that the simulation by XFEM is very validity.

4.2. Internal Crack Growth. The surface crack growth is discussed in the above section. Actually, the internal growth of crack gets more worthy of attention. It is very difficult to observe the internal crack growth law by means of experiment. Fortunately, the numerical simulation is a good way to research the internal crack growth. There are another two performance indexes that are employed to analyze the law of the internal crack growth. One is the crack length along direction of the thickness, and the other is the projected crack area that is two-dimensional area measurement of the fracture by projecting its shape onto the plane perpendicular to the length direction.

Figure 8 shows the relationship between the crack growth in depth direction and the fracture crack growth rates, and 


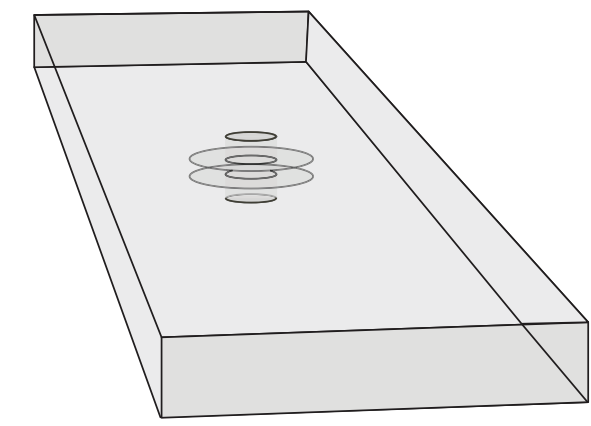

Stage I

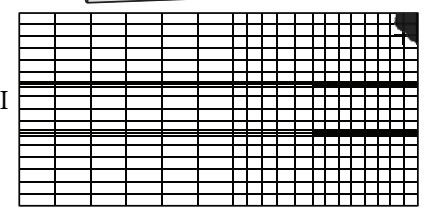

$n=739$

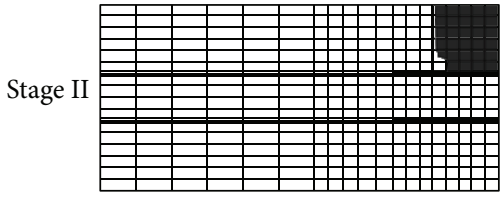

$n=2260$

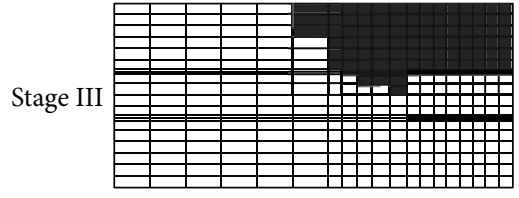

$n=15086$

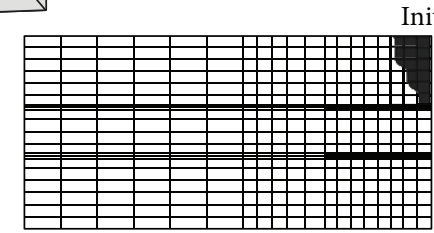

$n=1544$

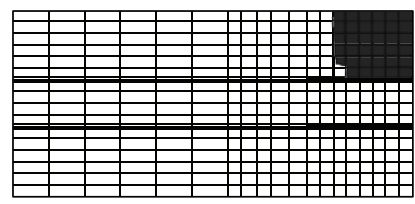

$n=3806$

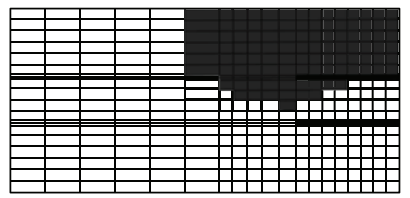

$n=16346$

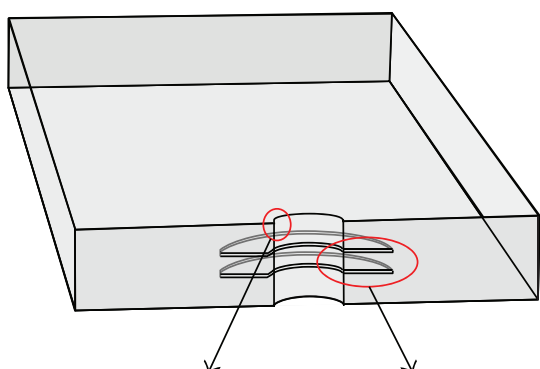

Initial crack location Nonwelded zone

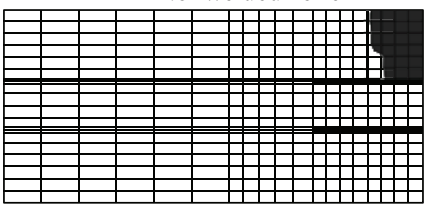

$n=2244$

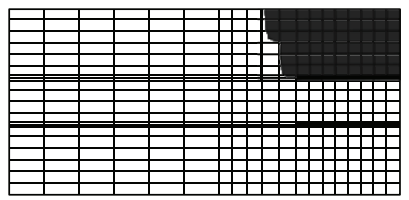

$n=7961$

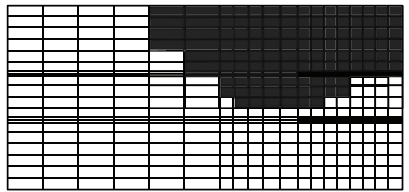

$n=17112$

FIGURE 3: The path of crack growth.

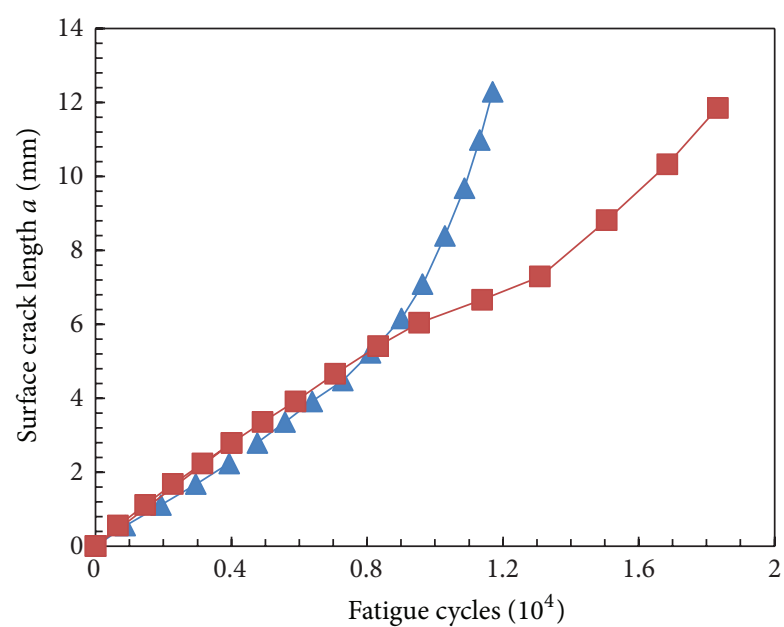

- - The model without nonwelded zones

$\rightarrow$ - The model with nonwelded zones

FIGURE 4: Surface crack length varies with fatigue cycles (forecast results).

Figure 9 shows the relationship between facture cycle times and the crack growth in depth direction. When there is no non-welded zone in DB interface, the crack growth rate in

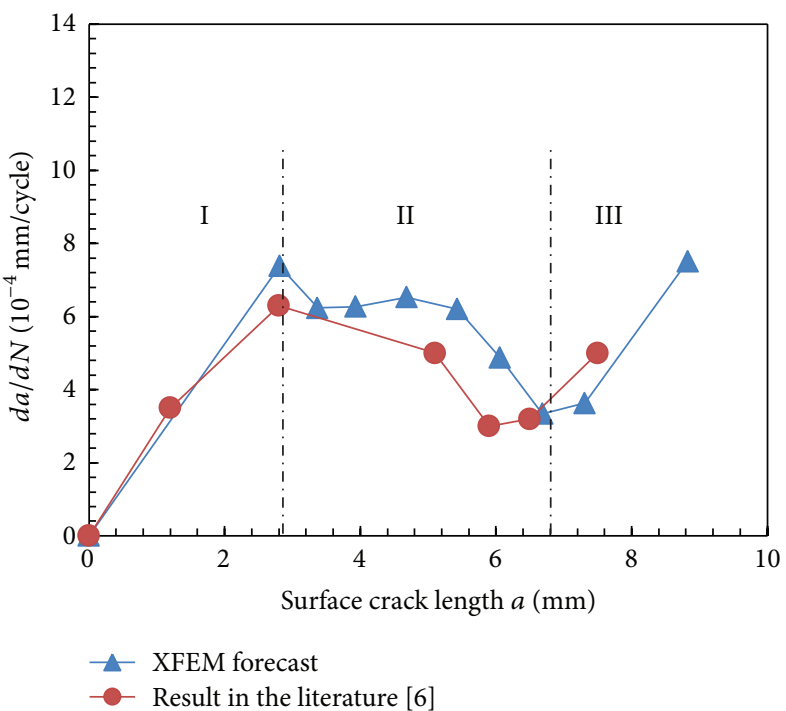

FIGURE 5: Crack growth rate varies with surface crack length.

depth direction increases rapidly and then is maintained in a high rate, so the crack length in depth direction also increases rapidly, as shown in Figures 8 and 9. By contrast, the crack growth rate decreases sharply when entering 


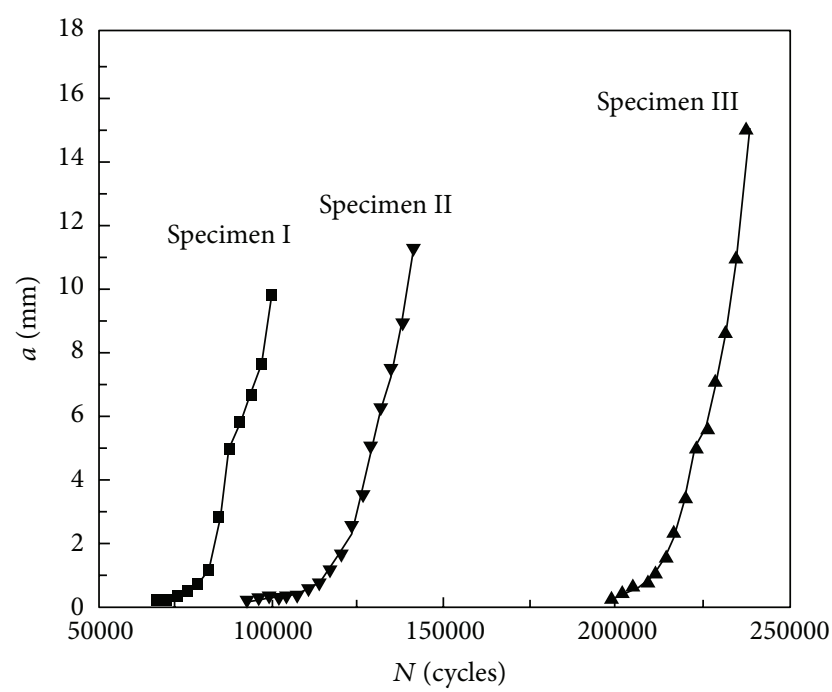

Figure 6: The relationship between crack length and cycles in the experimental results [6].

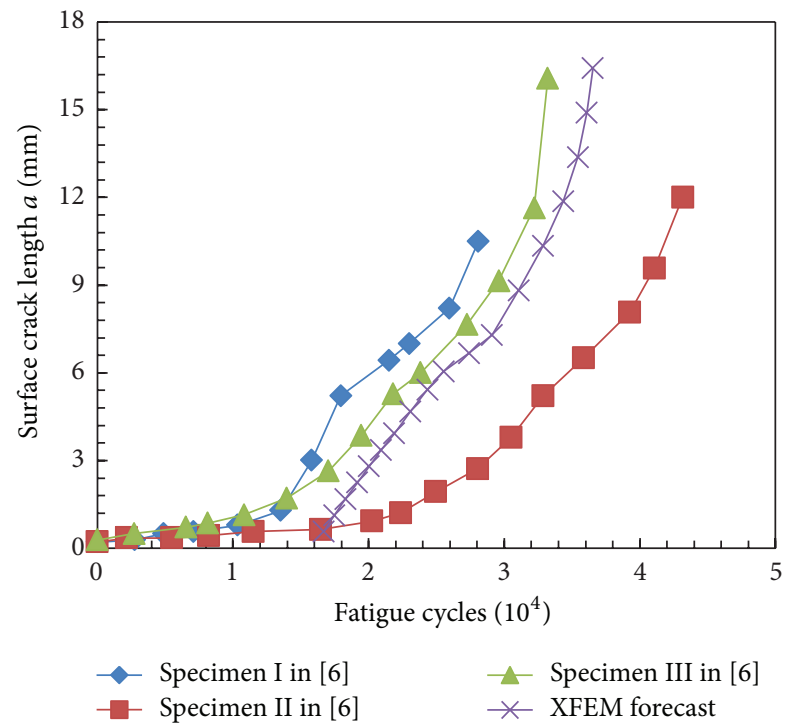

Figure 7: Crack growth length needed for the fatigue cycles.

the second stage of crack growth, and the fatigue cycles increase from 5000 times to 20000 times, and this indicates that there are three-fold increased fatigue life. These lines of evidence illustrate that the non-welded zone plays an important role in preventing the crack growth.

Actually, the internal crack growth happens along the direction of radius and depth at the same time. The projected crack area as a new parameter is employed to describe the internal crack growth. Similar with definition of the crack length growth rate, the projected crack area growth rate $\partial S / \partial N$ is defined, where $S$ is the projected crack area. Figures 10 and 11 give the relationship curves between the crack area and the cycle number and the relationship between crack area growth rate and the crack area. These lines of evidence also confirm that the non-welded zone plays an important role in preventing the crack growth.

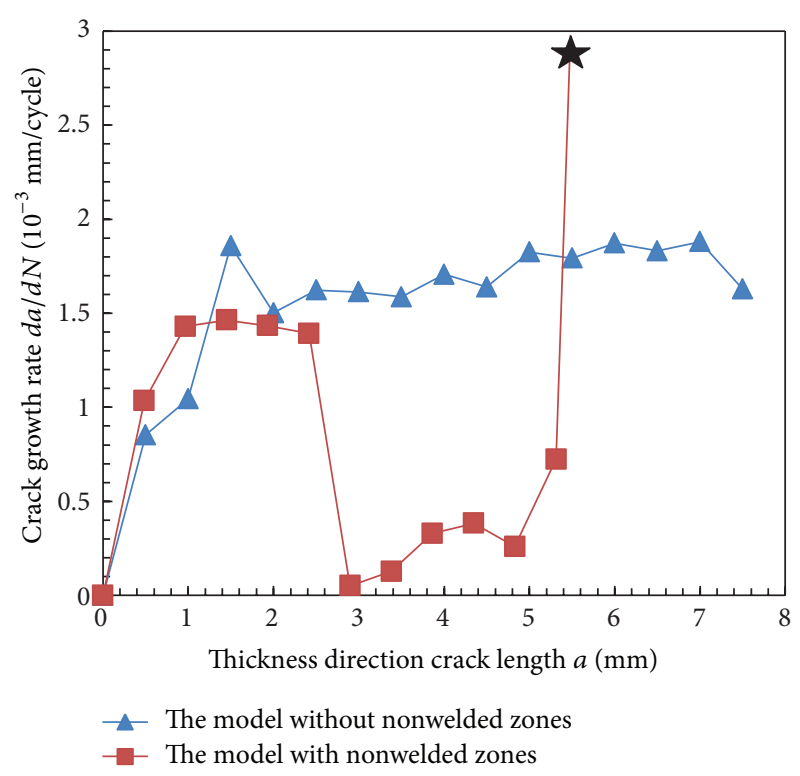

FIGURE 8: Fatigue crack growth rate varies with the crack length in depth direction.

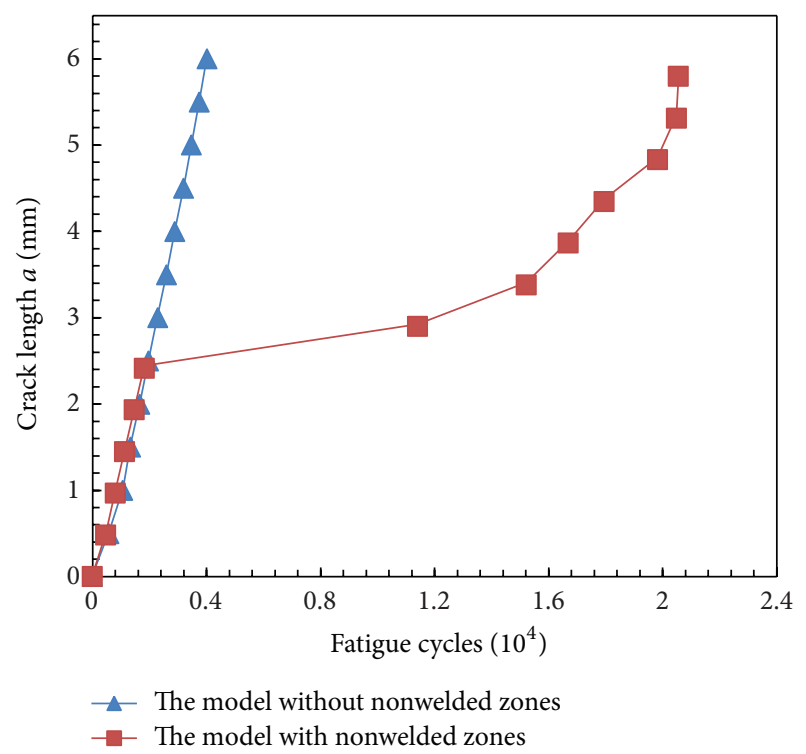

FIGURE 9: Crack length in depth direction varies with fatigue cycles.

4.3. Damage Tolerance Analysis. Damage tolerance is a property of a structure which relates to its ability to sustain defects safely until the structure is repaired. In ensuring the continued safe operation of the damage tolerant structure, inspection schedules are devised. Thus, the objective of damage tolerance design is to maximize the crack growth life so that more inspection periods can be undergone or to maximize the crack length with the same residual life so that it is easier to be detected.

The residual life under the different surface crack length is shown in Figure 12. Assuming the inspection interval is about 5000 cycles, the initial notched crack length is long enough to be detected. There are about 12000 cycle's times of the model without nonwelded zone, and it can experience 


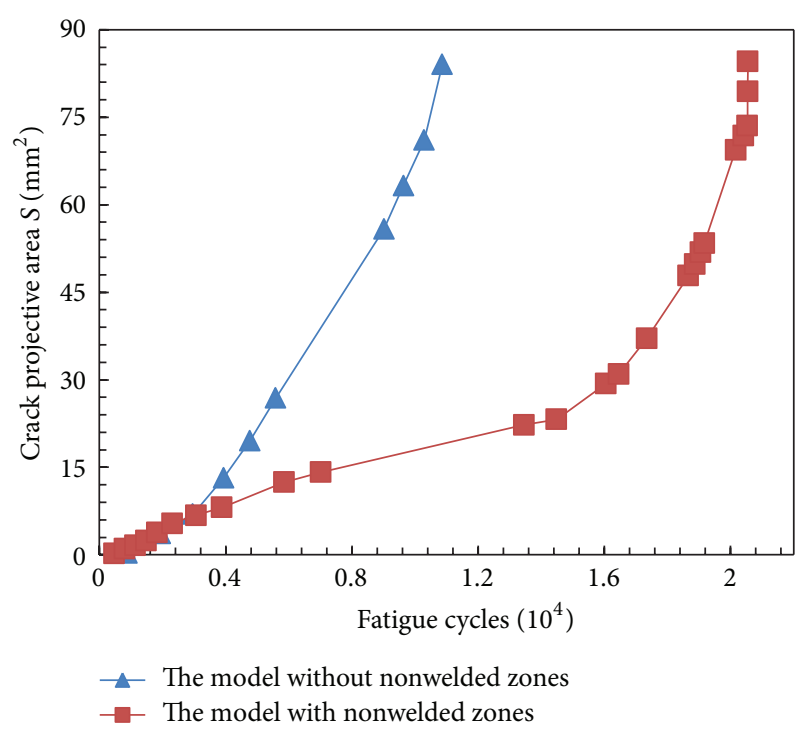

FIGURE 10: Projected crack area changes as fatigue cycles.

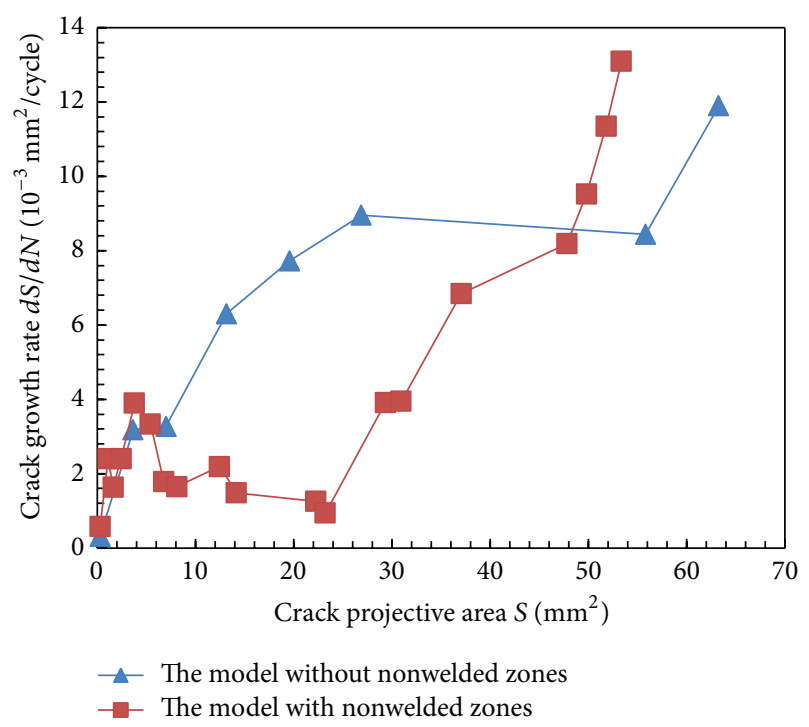

FIGURE 11: Fatigue crack growth rate changes as projected crack area.

two full inspection periods. By contrast, there are about 20500 cycle's times of the model with non-welded zone and it can experience four full inspection periods, which greatly improve the structure security. If the damage tolerance designs demand that there is at least one inspection period residual life left before detection, the limiting crack length should be $4 \mathrm{~mm}$ in the structure without non-welded zone and be $9 \mathrm{~mm}$ with non-welded zone, as shown in Figure 12. The non-welded zone makes the limiting length increase one time.

\section{Conclusions}

This paper analyzes the crack that grows in the diffusion bonded laminates of TC4 titanium alloy using XFEM based

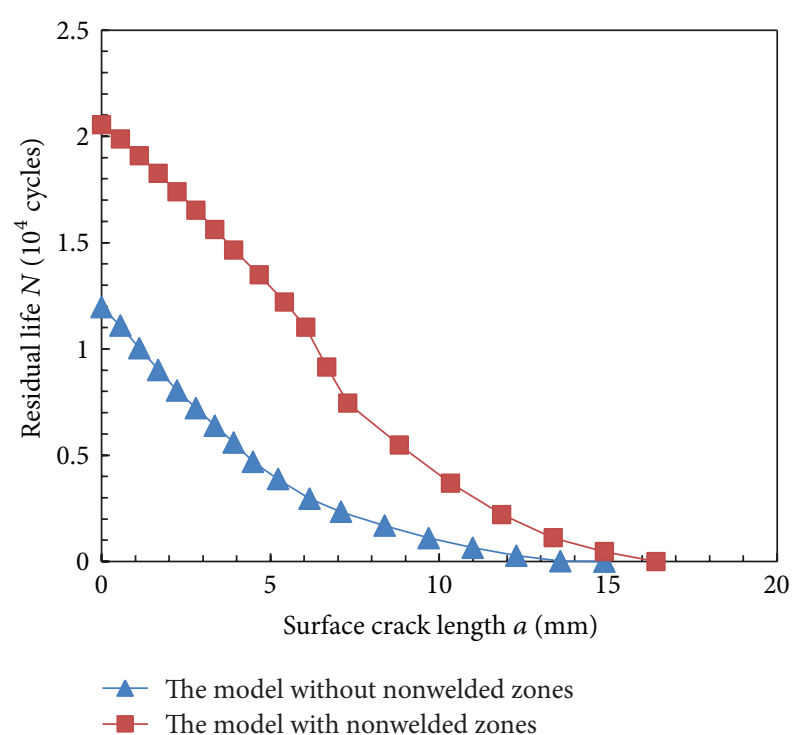

FIGURE 12: Structure of residual life changing with crack length along diameter direction.

on the ABAQUS platform and studies the crack growth law under the TC4 laminates. From the comparison between the predicted results and experiments, the XFEM can grasp the true crack growth law in the titanium-alloy laminates, and the XFEM is proved to be an efficient method to analyze the crack growth in the titanium-alloy laminates. In addition, through the analysis of the damage tolerance, the nonwelded zone set in the $\mathrm{DB}$ interface can significantly increase the fatigue life and improve the damage tolerance.

\section{Acknowledgments}

This research is supported by the National Basic Research Program (973Program) of China (Grant no. 2011CB610304), National Natural Science Foundation of China (11172052) and China Aviation Industry Research Project (CXY2011DG34).

\section{References}

[1] ASM Metals Handbook, vol. 2, ASM International, Materials Park, Ohio, USA, 10th edition, 1990.

[2] J. K. Wessel, The Handbook of Advanced Materials, Wiley Interscience, 2004.

[3] J.-K. Zhang, Z.-N. Li, Z.-P. Qiu et al., "Feasibility study on damage tolerance design of titanium alloys," Acta Aeronautica et Astronautica Sinica, vol. 30, no. 4, pp. 193-197, 2009 (Chinese).

[4] D. O. Cox and A. S. Tetelman, "Improved fracture toughness of a titanium alloy laminate by controlled diffusion bonding," Journal of Adhesion, vol. 5, no. 4, pp. 279-300, 1973.

[5] Z. Keyin, X. U. Lai, and L. Zhaorong, "Fatigue and fracture characteristics of titanium alloy boards bonded by diffusion," Journal of Mechanical Strength, vol. 20, no. 2, pp. 112-115, 1998 (Chinese).

[6] X.-F. He, Y.-M. Liu, W.-T. Liu, Y.-P. Sun, and X.-M. Wang, "Crack growth characteristic for diffusion bonded laminates of TC4 titanium alloy with localized no-welded area," Journal of Aeronautical Materials, vol. 31, no. 5, pp. 77-81, 2011 (Chinese). 
[7] T. Belytschko and T. Black, "Elastic crack growth in finite elements with minimal remeshing," International Journal for Numerical Methods in Engineering, vol. 45, no. 5, pp. 601-620, 1999.

[8] J. Shi, D. Chopp, J. Lua, N. Sukumar, and T. Belytschko, "Abaqus implementation of extended finite element method using a level set representation for three-dimensional fatigue crack growth and life predictions," Engineering Fracture Mechanics, vol. 77, no. 14, pp. 2840-2863, 2010.

[9] E. Giner, N. Sukumar, J. E. Tarancón, and F. J. Fuenmayor, "An Abaqus implementation of the extended finite element method," Engineering Fracture Mechanics, vol. 76, no. 3, pp. 347368, 2009.

[10] M. Stolarska, D. L. Chopp, N. Mos, and T. Belytschko, "Modelling crack growth by level sets in the extended finite element method," International Journal for Numerical Methods in Engineering, vol. 51, no. 8, pp. 943-960, 2001.

[11] S. Loehnert, D. S. Mueller-Hoeppe, and P. Wriggers, "3D corrected XFEM approach and extension to finite deformation theory," International Journal for Numerical Methods in Engineering, vol. 86, no. 4-5, pp. 431-452, 2011.

[12] N. Sukumar and J.-H. Prévost, "Modeling quasi-static crack growth with the extended finite element method-part I: computer implementation," International Journal of Solids and Structures, vol. 40, no. 26, pp. 7513-7537, 2003.

[13] China aeronautical materials handbook editorial board, China Aeronautical Materials Handbook, Standards Press of China, Beijing, China, 2001, Chinese.

[14] S. Osher and J. A. Sethian, "Fronts propagating with curvaturedependent speed: algorithms based on Hamilton-Jacobi formulations," Journal of Computational Physics, vol. 79, no. 1, pp. 1249, 1988.

[15] N. Moës, J. Dolbow, and T. Belytschko, "A finite element method for crack growth without remeshing," International Journal for Numerical Methods in Engineering, vol. 46, no. 1, pp. 131-150, 1999.

[16] N. Sukumar, D. L. Chopp, N. Moës, and T. Belytschko, "Modeling holes and inclusions by level sets in the extended finiteelement method," Computer Methods in Applied Mechanics and Engineering, vol. 190, no. 46-47, pp. 6183-6200, 2001.

[17] T. Belytschko, C. Parimi, N. Moës, N. Sukumar, and S. Usui, "Structured extended finite element methods for solids defined by implicit surfaces," International Journal for Numerical Methods in Engineering, vol. 56, no. 4, pp. 609-635, 2003.

[18] N. Moës, M. Cloirec, P. Cartraud, and J.-F. Remacle, "A computational approach to handle complex microstructure geometries," Computer Methods in Applied Mechanics and Engineering, vol. 192, no. 28-30, pp. 3163-3177, 2003.

[19] T.-P. Fries, "A corrected XFEM approximation without problems in blending elements," International Journal for Numerical Methods in Engineering, vol. 75, no. 5, pp. 503-532, 2008.

[20] J. Shi, D. Chopp, J. Lua, N. Sukumar, and T. Belytschko, "Abaqus implementation of extended finite element method using a level set representation for three-dimensional fatigue crack growth and life predictions," Engineering Fracture Mechanics, vol. 77, no. 14, pp. 2840-2863, 2010.

[21] E. M. Wu and R. C. Reuter Jr., Crack Extension in Fiberglass Reinforced Plastics, vol. 275, University of Illinois, 1965. 


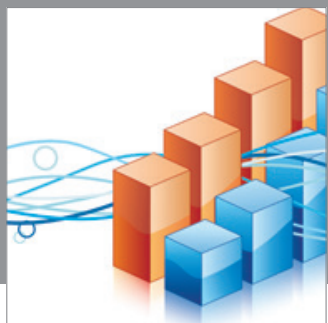

Advances in

Operations Research

mansans

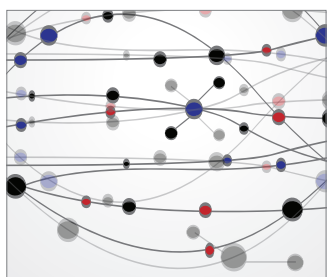

The Scientific World Journal
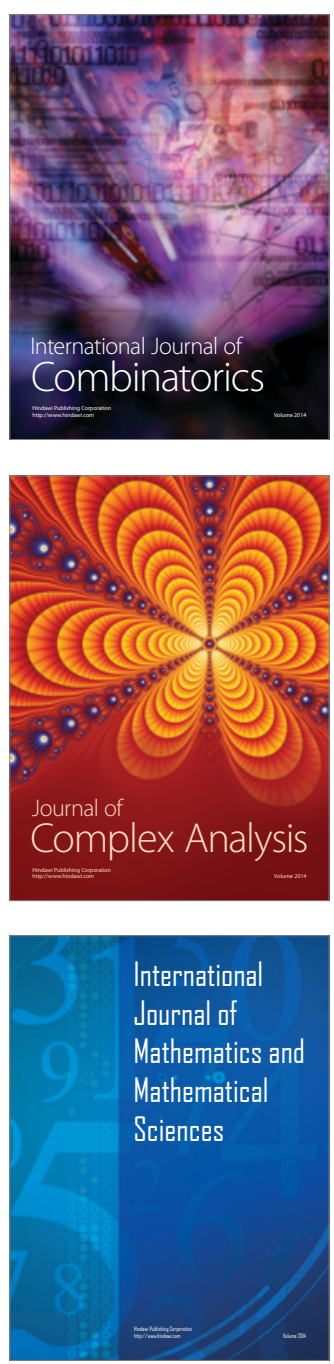
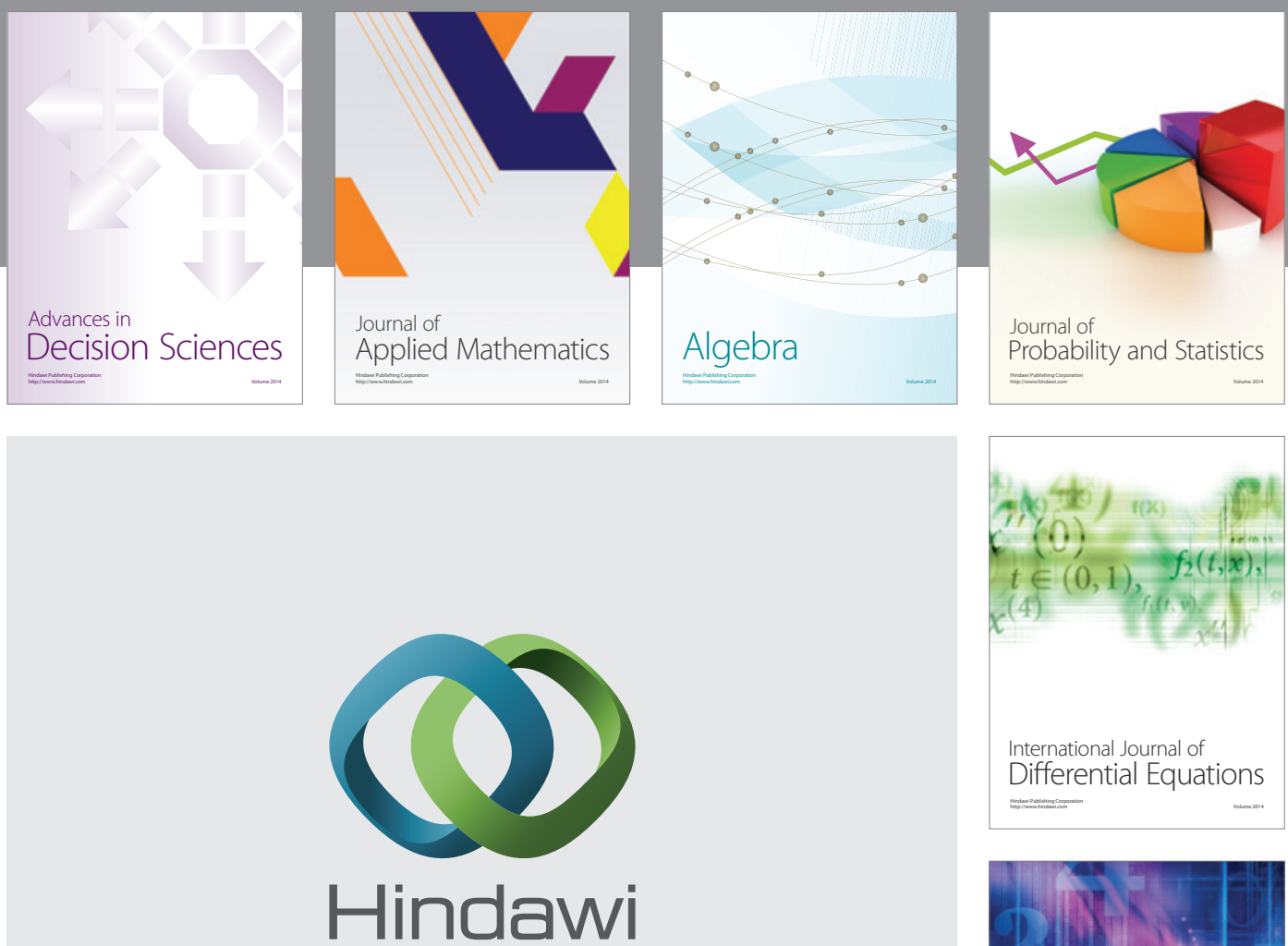

Submit your manuscripts at http://www.hindawi.com
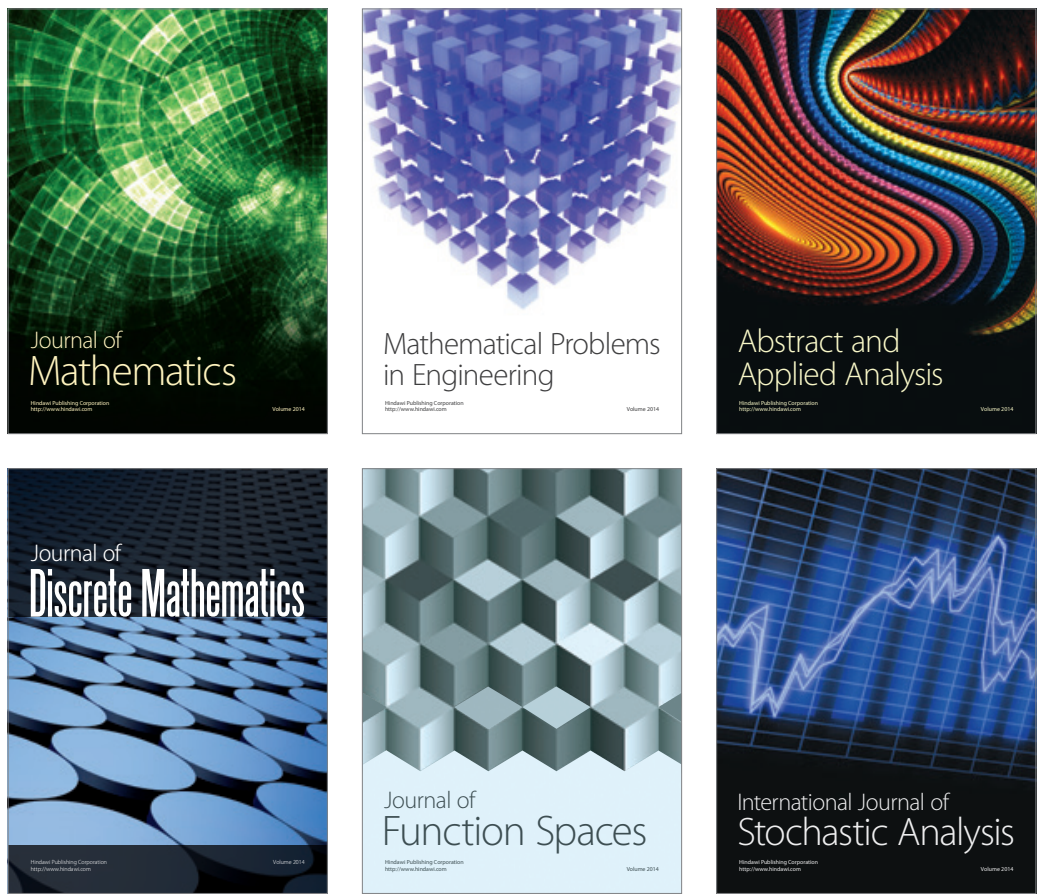

Journal of

Function Spaces

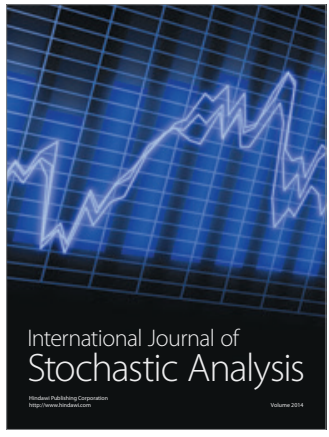

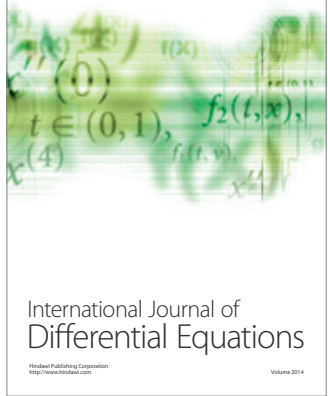
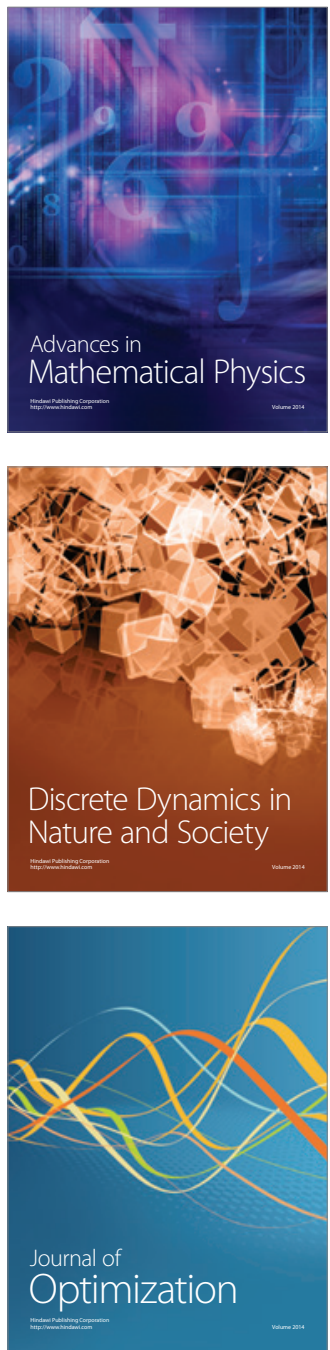